\title{
Computer Vision Approach for Detecting Adulteration of Ghee with Foreign Fats - A Survey
}

\author{
Aditya UPADHYAY a, ${ }^{\text {, Dr. Neha CHAUDHARY }}{ }^{\text {a }}$ \\ ${ }^{a}$ Manipal University Jaipu, India
}

\begin{abstract}
Ghee is pure clarified fat derived from milk, yogurt and fresh cream. It is most commonly used milk fat product in India. The consumption and production of ghee is consistently increasing by $10 \%$ in our country in every year. In comparison to other milk fat product, ghee is expensive and short in demand because of its pleasant taste or high nutrition value. Due to its high cost and demand in market, there are high possibilities to adulterate it with cheap fats like vegetable oil/animal body fats. The adulteration detection of ghee is becoming a serious issue to chemists. Several analytical and instrumental methods are available for the detecting adulteration in ghee based on chemical principles. On the basis of study, it was observed that analytical methods are not suitable to detect the adulteration level of $<15 \%$. In recent time, digital image analysis is introduced in the field of adulteration detection in food products. A very few studies found in the area of milk fat adulteration detection with foreign fats using image analysis. Various studies found related to detection of adulteration in Oils (like Extra virgin olive oil, sesame oil etc.) with cheap oil using the various color models (like CIELAB, RGB, HSV, CMYK) and machine learning algorithms.
\end{abstract}

keywords: - Ghee adulteration, Image analysis, Oil adulteration, Computer Vision, image analysis, physico-chemical, milk fat adulteration

\section{Introduction}

Clarified butter, or Ghee (Originated from Sanskrit word Ghrta), is the most widely used lipophilic dairy product (98.9\% lipids) in South Asian countries [2]. Mostly cow milk, buffalo milk is used to prepare ghee. Ghee is mostly used for frying and in cooking food because of its pleasant taste, delicious aroma and high nutrition value. It is also used in the preparation of traditional medicines and performing religion rituals. According to reports, $35-40 \%$ of produced milk is converted into Ghee and 170 thousand metric tons ghee produced in fiscal year 2020. But in summer season in India [3], a very complex situation arises due to fall in Milk production. In comparison to other dairy products, Ghee is expensive and high in demand. Therefore, it is highly susceptible to adulterate with Cheap vegetable fats, animal body fat and inedible Oils.

\footnotetext{
${ }^{1}$ Aditya Upadhyay, Department of Computer Science, Manipal University Jaipur, Rajasthan, India; E-mail: adityaupadhyay144@gmail.com.
} 
Other motives for adulterating Ghee are gaining more profit and to fill the gap between demand and supply. The detection of adulteration in ghee is very important because it is directly related to our health. Adulterated ghee contains hydrogenated fats, essence colors, carcinogenic chemicals that affects immune system, increase bad cholesterol, increases the risk of cancer.

\section{Methods for Preparing Ghee}

There is various method used commercially for preparing a ghee [7].

Indigenous Milk-Butter Process: - This method is mostly used at domestic level. In this method, Makkhan is used made by direct churning of yogurt at room temperature. Makkhan is placed in a vessel or ghee boiler and heated to about $110-120{ }^{\circ} \mathrm{C}$ with constant stirring in order to evaporate all the moisture. After that, the ghee is filtered using muslin cloth and packaged in containers.

Direct Cream heating Method: - In this method, fresh cream is heated in a stainlesssteel jacketed ghee vessel and heating end point can be determined manually based on the color of ghee residue. This method needs long heating time to remove moisture. After this, ghee is separated from ghee residue by the pressure filters and centrifugal separators. Then ghee is allowed to cool to $40-42{ }^{\circ} \mathrm{C}$ and then packaged in individual containers or tins.

Creamery Butter method: - In this method, butter is melted in a butter-Melter at $60^{\circ} \mathrm{C}$, and then pumped into a ghee boiler. In the boiler, the moisture in butter is evaporated with constant stirring to reach a temperature at $110-120{ }^{\circ} \mathrm{C}$. Further steps are same as above mentioned.

For all the above-mentioned methods, $110-120{ }^{\circ} \mathrm{C}$ temperature is suggested as clarification temperature for producing good quality of ghee. The crystalline phenomenon of high melting triglycerides and granularity of ghee is responsible for its purity and quality. The micro structure and textural properties of ghee are based on factors like crystallization, the existence of phospholipids and additives, milk fatty acid profile, clarification temperature followed by rate of its cooling.

Chemically, ghee is a complex lipid of glycerides, phospholipids, sterols, sterol esters, fat soluble vitamins, carbonyls, free fatty acids, hydrocarbons, carotenoids (available in cow ghee only). Glycerides constitute $98 \%$ of the total material. Granularity is also a measure of good quality ghee. A pure ghee should have a soft and granular texture and granularity of ghee appeared due to high melting triglycerides (HMT). Pure ghee texture is better because of bigger grain size and higher proportions $(9.0-12.0 \%)$ of high melting triglycerides (HMT). Commercially available ghee has poor granularity. There are various other factors on which the quality of ghee depends, such as

- Animal feed type

- Raw material used for producing ghee- makkhan, cream, white butter

- Method of preparation

- Clarification temperature

- Storage conditions of ghee 


\section{Various fats used for Adulteration}

Due to unique taste, high demand and high nutritional value, Ghee is expensive in comparison to other edible fats available in the market. It increases the chances of mixing cheap fats for economic advantages by traders. Various fats are used as an adulterant like: -

- $\quad$ vanaspati fats/oil, Refined oil like palm oil, Soyabean oil, coconut oil.

- animal body fats like lard or tallow

- mixture of animal body fats and plant oil

- mineral oils- solid paraffin and liquid paraffin

- Colors

\section{Adulteration Detection Method for Ghee}

For detecting adulteration in ghee by foreign fats, several analytical and instrumental methods are available. These methods are based on the determining of physical and chemical constants, specific fatty acids, fatty acid composition, glyceride structure and color reactions etc. Analytical methods [1][15], based on chemical principles, are Melting Point, Apparent Solidification time (AST) test, Baudouin test, Butyro Refractometer (BR) Reading, Critical temperature of dissolution (CTD), Reichert Meissl (RM) value, Iodine value, Polenske value, Saponification Value etc. Instrumental methods [19] like High Pressure Liquid Chromatography (HPLC), Spectroscopy, RP-TLC, Gas Chromatography (GC) are costly and need technical skills. Gandhi et. al. (2014) [20] coupled solvent fraction technique with RM value for the detecting presence of palm oil and animal body fat in ghee.

For the state of Rajasthan except Jodhpur district [17], FSSAI has prescribed the following standards for the quality of produced ghee: BR reading at $40 \mathrm{C}$ should be in the range of $40-43$, minimum RM value should be 26 , Baudouin test Negative, Maximum Moisture $0.5 \%$, free fatty acid (oleic acid) 3\%. Analytical methods are not capable in identifying all adulterants with different level of adulterations. Physico chemical constant values also varying geographically and seasonally. In Table 1, Physico chemical constants of pure cow and buffalo ghee are mentioned seasonally [7]. In Table 2, the values Physico-chemical parameters of pure cow, buffalo ghee and their mixture mentioned [7].

Table 1. Physico-Chemical constants of Cow and Buffalo pure ghee in different months of Year

\begin{tabular}{|l|l|l|l|l|l|l|l|l|l|l|l|l|l|}
\hline $\begin{array}{l}\text { Physico } \\
\begin{array}{l}\text { Chemical } \\
\text { constants }\end{array}\end{array}$ & Pure Cow ghee & Jan & March & May & July & Sept & Nov & Jan & March & May & July & Sept & Nov \\
\hline RM & 29.63 & 29.28 & 28.52 & 29.48 & 29.82 & 30.93 & 33.39 & 31.70 & 30.87 & 32.40 & 33.42 & 33.73 \\
\hline BR & 41.5 & 42.1 & 42.5 & 41.0 & 41.2 & 40.7 & 40.7 & 41.5 & 41.6 & 40.4 & 40.6 & 40.2 \\
\hline PV & 1.7 & 1.5 & 1.1 & 1.4 & 1.3 & 1.4 & 1.6 & 1.2 & 1.0 & 1.2 & 1.1 & 1.4 \\
\hline IV & 36.5 & 39.6 & 40.2 & 34.4 & 35.9 & 32.8 & 34.6 & 36.2 & 37.3 & 33.2 & 32.3 & 30.1 \\
\hline SV & 229.12 & 228.14 & 226.07 & 231.50 & 228.00 & 230.00 & 232.57 & 230.75 & 230.76 & 232.82 & 231.66 & 233.63 \\
\hline
\end{tabular}


Table 2. Physico-Chemical constants of Pure Cow ghee, pure Buffalo ghee \& (Cow+Buffalo) Ghee

\begin{tabular}{|c|r|r|r|}
\hline $\begin{array}{l}\text { Physico } \\
\text { Chemical } \\
\text { Constant }\end{array}$ & Pure Cow Ghee & \multicolumn{1}{|c|}{ Pure Buffalo Ghee } & Cow + Buffalo Ghee \\
\hline RM Value & $29.61 \pm 0.32$ & $32.59 \pm 0.46$ & $31.10 \pm 0.74$ \\
\hline BR Reading & $41.50 \pm 0.29$ & $40.83 \pm 0.25$ & $41.16 \pm 0.20$ \\
\hline PV Value & $1.40 \pm 0.08$ & $1.25 \pm 0.09$ & $1.33 \pm 0.06$ \\
\hline Iodine Value & $36.61 \pm 1.18$ & $33.98 \pm 1.09$ & $23.29 \pm 0.86$ \\
\hline $\begin{array}{c}\text { Saponification } \\
\text { Value }\end{array}$ & $228.81 \pm 0.76$ & $232.03 \pm 0.48$ & NA \\
\hline CTD & $51.6-54.6$ & $52.4-56.2$ & \\
\hline $\begin{array}{r}\text { AST (min-sec) at } \\
18^{\circ} \mathrm{C}\end{array}$ & $2-56$ to 3-26 & $2-30$ to 2-48 & \\
& & & \\
\hline
\end{tabular}

\section{Digital Image Analysis for food adulteration detection}

An image is made up of pixels arranged in matrix and these pixels can be seen by zooming an image [18]. A numerical value is assigned to each pixel in the range from 0 (black) to 255(White) representing pixel intensity value. All intermediate value between the range of 0-255 are different grey shades from black to white. It is expected that the mixing of any extraneous material, may changes pixel intensity which may changes the surface texture quantifiers of digital image of the food sample. This shows a scope in the domain of analysis of digital image as a technique for checking the quality of food products. In literature, many studies have used digital image analysis techniques for detection of adulteration in daily used food products like Butter, Cheese, Ghee, Ketchup, Oils, species, meat, milk, grains etc.

Lukinac et. al. (2018) [16] reviewed the application of digital image analysis in cheese quality evaluation. Reile et. al. (2020) [14] used the concept of color histograms with SPA-LDA for classification to detect the adulteration in ketchup with Sudan I dye. Sano et. al. (2003) detected adulteration in roast coffee powder using digital image processing. Justin et. al. (2017) [21] proposed an approach for the detection of adulteration in food items like oil, chilli powder, black pepper, milk and processed the images using MATLAB to extract feature like Mean, Standard deviation, Entropy, Smoothness, Texture feature using local tetra pattern.

In image processing [18][4], meaningful information of our use can be extracted from processed image by adding some values and performing mathematical operations on raw image. In this process, only rearranging of data is done. The area of image analysis lies between image processing and computer vision, without a clear-cut boundary.

\section{Literature Review}

With the advancement of technology, food adulteration detection methods are also changed with time. In now days, digital image analysis has become a relevant tool in food science. A very few studies have been found in the area of ghee adulteration detection using image analysis. Based on the studies, it is observed that image analysis 
methods provide better results than physico chemical methods in the detection of adulteration of ghee especially at levels $\geq 15 \%$.

Wasnik et. al. (2019) [3] proposed a model for detection of adulteration level of vegetable fat in cow ghee using image analysis. A concept of multiple regression was used to detect adulteration level with four selected features (pixel intensity, branches, luminance and equivalent diameter). For the study, samples of cow ghee with different level of adulteration $(0 \%, 5 \%, 10 \%, 15 \%, 20 \%)$ with vegetable fat were prepared. Images were captured using flatbed scanner (Canon Canoscan 9000F Mark II) in transmission mode and saved in TIFF format. Total 105(5 samples $\mathrm{x} 3$ replications $\mathrm{x} 7$ days) captured images were analyzed using ImageJ software and Adobe photoshop in L-a-b mode.

Wasnik et. al. (2017 a) [1] derived skeleton parameters (branches, junctions, end point voxels), texture parameters (fractal dimension) and morphological (pixel intensity, particle count, equivalent diameter) of 105 images using ImageJ software. Using the defined image analysis protocol, results shows that pixel intensity, fractal dimension and skeleton parameters were found vary significantly with coefficient of determination $>0.95$ to detect level of adulteration.

Wasnik et. al. (2017 b) [2] extracted particle count, equivalent diameter and color parameters of 105 sample images using ImageJ software and Adobe photoshop in lab mode respectively. CIELAB parameters $\left(L^{*}, a^{*}, b^{*}\right)$ were calculated using the value of $\mathrm{L}, \mathrm{a}, \mathrm{b}$ parameters. From the extracted values of CIELAB $\left(\mathrm{L}^{*}, \mathrm{a}^{*}, \mathrm{~b}^{*}\right)$, color descriptors like hue, chroma, yellowness index and whiteness index were calculated. The result shows that particle count, luminance, equivalent particle diameter and whiteness index can be considered for detecting adulteration level of vegetable fat in cow ghee.

Ayari et al. (2018) [12] used electronic nose (e-nose) with PCA and ANN for detecting adulteration in cow ghee with sunflower oil and cow body fat. E-nose devices mimic the sense of smell and uses a sensor's array to detect and differentiate odors precisely at low cost. For study, Test samples were created by adding sunflower oil and cow body fat in cow ghee in proportions of $10 \%, 20 \%, 30 \%, 40 \%, 50 \%$ with 15 replications for each adulteration level. The result showed that ANN correct classification rate was $82.5 \%$ and $91.3 \%$ for cow body fat and sunflower oil, respectively.

Karla et. al. (2015) [13] proposed a methodology based on images analysis and multivariate classification based on discriminant analysis for the detection and classifying extra virgin olive oil (EVOO) samples with respect to brand and adulteration with soybean oil. For classification purpose, RGB color space is used with linear discriminant analysis (LDA) in association with successive projections algorithm (SPA). With full histogram, partial least squares-discriminant analysis (PLS-DA) was employed. For the study, total 53 EVOO samples was collected with three different brand and 99 adulterated samples with soybean oil having different level of adulteration.

Mahdi Rashvand et. al. (2019) [11] used ANN with different hidden layers for the detection of adulteration in Sesame Oil with sunflower oil and Canola oil. MATLAB was used for image processing and RGB, CMY, $\mathrm{L}^{*} \mathrm{~A} * \mathrm{~B} *$ color components were used for the study. 
Marchal et al. (2013) [9] proposed an approach for detecting adulteration in olive oil samples based on computer vision and ANN. For the study, the authors used three different input parameters which was the histogram of every channel of the image in three color spaces: CIELAB, RGB, and HSV, and four feature extraction methodsPrincipal Component Analysis, Kernel PCA, Linear Discriminant Analysis and Kernel LDA.

Karagiorgos et. al. (2017) [8] developed image processing algorithm for detecting adulteration of soybean oil in olive oil from captured image. Later this algorithm was planned to be implemented into mobile application of smart phones, where anyone can measure the olive oil quality by taking the picture of samples by smart phones. For determining the adulteration percentage in sample, the captured image was divided into two parts- first part contains the oil sample area and another part contains the rest of the image. For the study, 11 different adulterated samples were prepared having $0 \%$ to $100 \%$ with the step of $10 \%$ and three images captured for each sample. CIELAB color space was used to design a model for the prediction of adulteration percentage with $3 \%$ to $5 \%$ absolute error.

Table 3 Review Studies

\begin{tabular}{|c|c|c|c|c|}
\hline Author & Base product & Adulterant & Methods & Accuracy \\
\hline Wasnik et al. (2019) & Ghee & Vegetable fat & Multiple regression & $92.2 \%$ \\
\hline Ayari et al. (2018) & Ghee & $\begin{array}{l}\text { Sun flower oil } \\
\text { and cow body } \\
\text { fat }\end{array}$ & $\begin{array}{ll}\text { electronic } & \text { nose } \\
\text { method with } & \text { PCA } \\
\text { and ANN } & \\
\end{array}$ & $\begin{array}{l}91.3 \% \text { (for sun } \\
\text { flower oil), } 82.5 \% \\
\text { (for cow body fat) }\end{array}$ \\
\hline Karla et al. (2015) & $\begin{array}{l}\text { Extra virgin } \\
\text { olive oil }\end{array}$ & Soybean oil & $\begin{array}{l}\text { SPA-LDA and PLS- } \\
\text { DA }\end{array}$ & $\begin{array}{l}--100 \% \text { according to } \\
\text { brand }(\mathrm{A}, \mathrm{B}, \mathrm{C}) \\
\text {--For brand A, } \\
88 \%(\mathrm{SPA}-\mathrm{LDA}), \\
94 \%(\mathrm{PLS}-\mathrm{DA}) \\
-- \text { For brand B and } \\
\text { C, } 100 \% \text { in both } \\
\text { models }\end{array}$ \\
\hline $\begin{array}{l}\text { Mahdi Rashvand et } \\
\text { al. (2019) }\end{array}$ & Sesame Oil & $\begin{array}{l}\text { Sunflower oil } \\
\text { and Canola Oil }\end{array}$ & $\begin{array}{l}\text { ANN with different } \\
\text { hidden layer }\end{array}$ & $\begin{array}{l}\text { 12-6-7 for } \\
\text { Sunflower oil, 12- } \\
10-7 \text { for canola oil }\end{array}$ \\
\hline Marchal et al. (2013) & $\begin{array}{l}\text { Virgin Olive } \\
\text { Oil }\end{array}$ & Impurities & ANN, SVM & $\begin{array}{l}87.66 \% \text { (SVM with } \\
\text { KPCA), } 82.38 \% \\
\text { (ANN with PCA) }\end{array}$ \\
\hline
\end{tabular}

\section{Conclusion}

Milk fat adulteration is a serious issue for chemist in now days because it is directly related to our health. Several analytical and instrumental methods are available for detecting adulteration in milk fat or ghee. But these methods are not capable to detect all kind of adulterants. The values of physico- Chemical parameters like RM value, BR reading, CTD, AST, PV, IV, SV is influenced by season, storage conditions and many more factors. Image analysis is new tool in the domain of food adulteration detection and provide better results in comparison to existing methods. 


\section{References}

[1] Wasnik PG, Menon RR, Surendra Nath B, Balasubramanyam BV, Manjunatha M, Sivaram M (2017a) Application of particle analysis and colour parameters for detection of adulteration of cow ghee with vanaspati derived from image analysis. Indian J Dairy Sci 70(2):200-208

[2] Wasnik PG, Menon RR, Surendra Nath B, Balasubramanyam BV,Manjunatha M, Sivaram M (2017b) Application of pixel intensity, fractal dimension and skeleton parameters for detection of adulteration of cow ghee with vanaspati derived from image analysis. Indian J Dairy Sci 70(3):331-337

[3] Wasnik PG, Menon RR, Surendra Nath B, Balasubramanyam BV, Manjunatha M and Sivaram M (2019) Development of mathematical model for prediction of adulteration levels of cow ghee with vegetable fat using image analysis. J Food Sci Technol 55: 2320-2325

[4] Yam KL, Papadakis S (2004) A simple digital imaging method for measuring and analyzing colour of food surfaces. J Food Eng 61(1):137-142

[5] Ropadi AI, Pavlidi DE, Mohareb F, Panagou EZ, Nychas GJE (2015) Multispectral image analysis approach to detect adulteration of beef and pork in raw meats. Food Res Int 67:12-18

[6] Sano EE, Assad ED, Cunha SAR, Correa TBS, Rodrigues HR (2003) Quantifying adulteration in roast coffee powders by digital image processing. J Food Qual 26:123-134

[7] Kumar, A. (2008) Detection of adulteration in ghee. Ph.D. Thesis submitted to National Dairy Research Institute (Deemed University), Karnal, India.

[8] Karagiorgos N, Nenadis N, Trypidis D, et al. (2017) An approach for estimating adulteration of virgin olive oil with soybean oil using image analysis. Published in: 2017 6th International Conference on Modern Circuits and Systems Technologies (MOCAST), Thessaloniki, Greece, 1-4.

[9] Marchal PC, Gila DM, García JG, et al. (2013) Expert system based on computer vision to estimate the content of impurities in olive oil samples. J food Eng 119: 220-228.

[10] Silva SF, Anjos CAR, Cavalcanti RN, et al. (2015) Evaluation of extra virgin olive oil stability by artificial neural network. Food Chem 179: 35-43.

[11] Mahdi Rashvand, Abbas Akbarnia. The feasibility of using image processing and artificial neural network for detecting the adulteration of sesame oil[J]. AIMS Agriculture and Food, 2019, 4(2): 237 243. doi: 10.3934/agrfood.2019.2.237

[12] Ayari F, Mirzaee-Ghaleh E, Rabbani H, Heidarbeigi K. Detection of the adulteration in pure cow ghee by electronic nose method (case study: sunflower oil and cow body fat). Int J Food Prop 2018; 21(1):1670-9; https://doi.org/10.1080/10942912.2018.15057 55

[13] K.D.T. De Melo Milanez, M.J.C. Pontes, Classification of extra virgin olive oil and verification of adulteration using digital images and discriminant analysis, Anal. Methods. 7 (2015) 8839-8846. doi:10.1039/c5ay01765c

[14] Reile CG, Rodríguez MS, Fernandes DDS, Gomes AA, Diniz PHGD, Di Anibal CV. Qualitative and quantitative analysis based on digital images to determine the adulteration of ketchup samples with Sudan I dye. Food Chem. 2020 Oct 30;328:127101. doi: 10.1016/j.foodchem.2020.127101. Epub 2020 May 20. PMID: 32480258.

[15] Hazra T, Sharma V, Saha P and Parmar M (2017a) Physico-Chemical Properties Analysis Based Approaches to Ascertain the Purity of Ghee- A mini Review. Int J Sci Env 6: 899 - 907

[16] Lukinac J. Jukić M. Mastanjević K. Lučan M. 2018 Application of computer vision and image analysis method in cheese-quality evaluation: a review Ukrainian Food Journal 7(2) pp 192-214 DOI: 10.24263/2304-974x-2018-7-2-4

[17] https://www.fssai.gov.in/upload/uploadfiles/files/Compendium_Food_Additives_Regulations_29_03_2 019.pdf

[18] Wasnik, P.G.; Menon, R.R.; Meshram, B.D. Digital Image Analysis: Tool for Food Quality Evaluation.In Processing Technologies for Milk and Milk Products, 1st ed.; Agrawal, A.K., Goyal, M.R., Eds.; Apple Academic Press: Florida, FL, USA, 2017; pp. 65-104.

[19] Anupama R, Sharma V, Arora S, Lal D, Anil K (2015) A rapid reversed phase thin layer chromatographic protocol for detection of adulteration in ghee (clarified milk fat) with vegetable oils. J Food Sci Technol 52(4): 2434-24

[20] Gandhi K, Upadhyay N, Aghav D, Sharma V, Lal D (2014) Detection of adulteration of ghee (clarified milk fat) with palmolein and sheep body fat using Reichert-Meissl (RM) value coupled with solvent fractionation technique. Indian J Dairy Sci 67 (5): 387-393. 
[21] A. Justin Diraviam, G. Angel and K. Rajappan, 2017. A Novel Method in Detection of Food Adulteration in Selected Food Items using Digital Image Processing Technology with Digital Camera. Asian Journal of Information Technology, 16: 374-382. 